\title{
LII. A reply to Earl Stanhope, on his defence of certain principles and facts erroneously stated in his stereotyped "Principles of the Science of Tuning Instruments with fixed Tones."
}

\author{
Mr. John Farey
}

To cite this article: Mr. John Farey (1809) LII. A reply to Earl Stanhope, on his defence of certain principles and facts erroneously stated in his stereotyped "Principles of the Science of Tuning Instruments with fixed Tones." , Philosophical Magazine Series 1, 33:132, 292-299, DOI: $10.1080 / 14786440908562870$

To link to this article: http://dx.doi.org/10.1080/14786440908562870

$$
\text { 曲 Published online: } 18 \text { May } 2009 .
$$

Submit your article to this journal 5

Џll Article views: 3

Q View related articles $\asymp$ 
correct figure to a convex than to a plane speculum; and it is well known to practical opticians, that the errors of one spberical speculum often correct those of the other.

If any real advantages arise from shortening the tubes of reflecting telescopes, it becomes a matter of importance that refracting telescopes should possess similar properties. By means of the following contrivance the tubes of refractors may be so much shortened as to be only one third of the focal length of the object-glass. A plane speculum $C D$, whose diameter is two-thirds of that of the object-glass $A B$, is so placed that $\mathrm{CA}$ is one-third of the focal length of $\mathrm{AB}$. By giving a small inclination to $C D$, the rays are reflected to a second plane speculum EG, equal to one-third of the diameter of $A B$, which again reflects the incident rays to $F$, where the image is formed and magnified by the eye-piece. In this construction, the only disadvantage is the loss of light occasioned by two reflections; but this may be obviated by increasing the aperture of the object-glass, and is by no means such a serious evil as that which arises in M. Burckhardt's contrivance, from the loss of such a large central portion of the great speculum.

I am, dear sir, your most obedient servant,

D. Brewster.

To Mr. Tilloch.

LII. A Reply to Earl Stanhope, on his Defence of certain Principles and Facts erroneously stated in his Stereotyped "Principles of the Science of Tuning Instruments with fixed Tones." By Mr. John Farey.

"The difference between a man of real science, and one who has the ambition to be thouglit so, is very great."-EARE STANHopz.

To Mr. Tilioch, - Sir,

$T_{\text {HE truths and principles of the Mathematical Sciences }}$ are not in any instance to be yielded to authority, however imposing its aspect; neither should we suffer any other considerations, long to restrain our efforts, in defending their 
just cause. It has been purely out of regard and tenderness to the unfortunate situation of a musician of the very first rank, whose mental aberrations bad been much aggravated by the part he was led to take, and made appear to act, in explaining and defending a noble Earl's reveries on the subject of Tuning musical Instruments, that $I$ have been so long kept back from replying to such parts of the two Letters of Earl Stanhope, printed in your Magazine (vol. xxviii. p. 144, and xxx. p. 34, ) as relate to the scientific principles of Tuning: and similar feelings towards the very respectable individual alluded to, alone induce me to refrain from again touching on the two "Plain Statements," and the "Narrative," further than to declare, as in justice to Dr. C.'s musical reputation I think I ought, that he never, I believe, perused or saw the Stanhopian "Plain Statement," mentioned by His Lordship in vol. xxx. p. 25, previously to its publication*, except in the hands of Mr. Ferguson, from whom he refused to take the proof sheets, or look at them: but, as Mr. F. himself told me, directed him to take them again to the printer; intending, as he (Dr. C.) bas often told me, that His Lordship should be responsible for what he had written and got printed, and not suspecting, under the circumstances, that the name of $J$. W. Calcott would be affixed to it when published. After this, there needs no more for me to say at present, than request those who happen to have the two pamphlets, to compare them together, as the worthy and unfortunate Doctor intended, by stitching up and distributing them, as I mentioned in a former communication.

There are six questions touched upon in His Lordship's two Letters referred to, on each of which I wish to be indulged in saying a few words :- these are shortly, 1st, Whether a monochord board should be divided into 120 or 100 parts?

$2 \mathrm{~d}$, Whether the difference of the lengths of string, can accurately measure the interval between the sounds of two strings, of the same size, weight, and tension?

* Indeed I saw Dr. C. write a Note to you, Sir, to this effect, in February 1808, with an irtent that you should piblish this fact in your Magazine. 
$3 \mathrm{~d}$, Whether four or five columns are to be found in pages 7 and 22 of the Sterestype pamphlet?

4th, Whether the intervals called the four tierce wolves are of the same or different magnitudes?

5 th, Whether equal temperaments of successive concords of the same kind, produce equality in the rates of their leating?

6th, Whether the notation of musical intervals generally, by $\Sigma, f$ and $m$, rather than by their most simple ratios, be analogous to substituting a notation by scores, dozens, and odd, in place of the universally received decimal notation?

I.- In addition to the reasons I have given at page 192 of vol. xxvii., for preferring a decimal division of the monochord, I have further to remark, on what bas fallen from His Lordship (page 144 of vol. xxviii.) that those "important lengths" which His Lordship's scale is calculated to show in round numbers, are perfectly unimportant; for, what person using a monochord, other than as a play-thing, wants to use the scale attached to the string at all, in tuning a perfect concord of any kind? And does not the use of its scale as a tuning apparatus wholly consist, in either setting or taking off tempered intervals? And whether is it easiest, to set a triequal quint for instance, on a decimal scale by $\mathbf{m y}$ number $\cdot 6694329$, or on His Lordship's scale of 120 , by means of his vulgar fractions $\frac{2,00898,850+}{3,00000000}$ (Stereotypepage

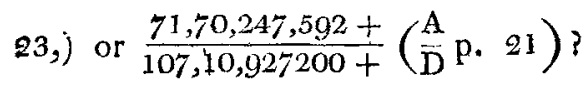

II.-I have maintained (and am backed by all mathematical writers) that it is ratios only, and not lengths, except of such things as in their nature measure ratios, as logarithm scales \&c. do, that can deune musical intervals. And though His Lordsiip expressly assetts (p. 145, vol. xxviii.) that "deviations from perfect intervals are concisely, as well as accurately and conveniently expressed, by means of the difference of the lengths of wires," I shall take the very example which he alludes to, (Stereotype p. 8,) wherein it is said, that 1.44 the difference of two strings, of which the 
actave length is $120^{\circ} 00$, "sliows the value" of the lierce wolf; in order to show, that $\frac{144}{12000}$, instead of expressing an interval called the enharmonic diesis $(21 \mathrm{\Sigma}+2 \mathrm{~m})$ as it ought to do, represents an interval exceeding 6 octaves by a superfluous third $(3905 \Sigma+77 f+338 \mathrm{n})$ !

III.-Five columns certainly appeared to my eyes, when I was commenting on the Stereotype pages 7 and 22 , therefore, unluckily it should seem, I mentioned five; but have I anywhere said or insinuated, that His Lordship therefore intended to represent five wolves, besides that produced by the quints? Aud I could not myself have intended to represent five such wolves, when his Lordship is severe upon me for saying there are but two in all. His Lordship's sarcasms, about dividng is into 5 aliquot parts, might therefore have been spared.

IV.-My arguments for the exact equality of all His Lordship's four ticree wolves, (at $\mu_{2}$ e 200 , vol. xxvii.) retain their force, and are not invalidated by what His Lordship has advanced at page 149, vol. xxviil.; where, fortunately, His Lordship has let us into the secret of his blunders in this respect, by the mention of " monochord lengths," showing, that when His Lordship argues for as complete a distinction between his tierce wolves, as to magnitudes, as between half-guineas, half-crowrs, sixpences, and halfpence, he had no better ground than their different lengths on the monochord; forgetting what I had endcavoured to impress on him, under the second head above, as to the fallacy of these lengths as a test of the magnitudes of intervals. Could not His Lordship as easily "distribute" or divide the same interval in four different ways in his C G D and $\mathrm{A}$-columns; as he can so distribute four different intervals? unless he confines his idea of equality, to monochord lengths, as then of course, they would only fit where the octave and thirds are also of the proper proportionate lengths? Absurdities, to which His Lordship surely could not have turned his attention.

V.-I did think it possible, when writing my observations page 201 to 203, vol, xxvii., that slips of His LordT 4

ship's 
ship's pen had occasioned his appearing to advance a doctrine, so opposite to all that had been demonstrated by $\mathrm{Dr}$. Smith, Dr. Robison, and a host of other mathematical writers; but his defence of the same in pages 150 to 152, vol. xxviii., precludes any such charitable suppositions in future. The scientifit terms, or rather the "scientific jargon," of His Lordship, I certainly do not understand, if by that he means, that I am to receive them, in opposition to the authorities above quoted, by whom His Lordship was certainly not "obliged to use" his new terms, for they have uniformly and consistently used pulses or vibrations for what His Lordship would now for the first time call beats and what he would exclusively call beatings they have generally called beats, but have sometimes used leatings as synonymous therewith.

Before His Lordship took pen in hand on this subject, I well knew that the rate of beating increased along with every increase of the imperfection of a consonance; but His Lordship is the only one I ever heard assert, that it increases "As the imperfection increases," which is no more true, than that the sine of an angle increases as the angle increases, or that gravity increases as the distance decreases. His Lordship refers (page 151,) to an example, and attempts to prove, that the triequal quints $\mathrm{DA}$, one an octave above the other, leat equally quick: let us therefore see what evidence numbers furnish in this case. By referring to my table in page 5 , vol. $\times x \times$. it will appear, that the two D's vibrate or excite 134.44 and 268.88 complete pulses in the air in one second of time respectively, and the two A's 200.83 and 401.66 pulses respectively, and by using these in the proper theorem for the purpose, we get 1.666 beats per second made by the lower, and 3.333 beats per second by the upper of these tempered or tri-equal quints; the one just doulle of the other, instead of their being equal as our noble author has maintained; and thus we see, that no "beating between the two beatings" could in this case happen even in theory, and certainly none in practice could be expected; for who besides Earl Stanhope ever talked of hearing beatings, between two noises which themselves occur but $1 \frac{2}{3}$ and $3 \frac{1}{3}$ times 
times per second! or not above one-eighth of the rate neces. sary to constitute continuous or musical sound? In the case of equally tempered interva!s, situate at the exact distance of any of the concords from each other, it is generally true, that no "beating between the beatings" either in theory or practice can happen. Suppose for instance, His Lordship's minor sixth $\mathrm{CA}$ which is flattened about $\frac{21}{22}$ parts of a comma (not $\frac{20}{21}$ as printed by mistake p, 195, vol. xxvii.); this in the middle septave beats 22.6335 times per second (or rather, in practice won't beat at all, but produce a continuous third discordant note): if we tune another similar or equally tempered sixth, on a note, a true minor sixth below C the bass of the former one, that is, on His Lordship's first bass $\mathbf{E}$ : we shall find, that this will beat just 5 -eighths as fast as the above, or 14.1459 times per second, but no " beating between the beatings" will take place, although each are quick enough, to produce them, owing to their having the true relation of minor sixth between them, and not because they are unisons as His Lordship would contend. Let us, however, abandon the supposition of the tempered sixths having basses that are exactly at conçordant distances, and tune just a similar minor sixth below $\mathrm{C}$ to that which His Lordship has above $\mathrm{C}$, that is, take two of these 6ths in succession; then we shall find, the lower note $\mathrm{E}$ making 151.79 vibrations per second, and the th EC will beat at the rate of $14 \cdot 3144$ times in a second: which not bearing a true concordant relation to the beating of the upper 6 th, the sounding of the two together will be found by calculation to occasion a "beating between the beatings" at the rate of 1.3477 per second : thus we see, that a "beating between the beatings" may happen to equally tempered concords: and the same will indeed always happen, in theory at least, to the tempered concords of which $\mathrm{His}$ Lordship treats (although His Lordship asserts the contrary); for all his tuning is to be performed by perfect intervals except two successive biequal thirds, and three successive triequal quints, all of which will have such a " beating between 
the beatings," and of course so acute an observer as His Lordship cannot fail of perceiving them: and will be necessitated to "beat" a retreat, out of the labyrinth of error into which he has with temerity advanced, instead of thinking to "beat" his pretended "facts" and " important musical truths" into me, or any one else who has the least pretensions to mathematical knowledge.

V1.-I have here to complain of the same superficial view of the subject, as His Lordship took when commenting on decimally divided monochords : the object of any general notation of musical intervals cannot be to represent the perfect concords, as $\frac{1}{2} \frac{2}{3}, \frac{3}{4}, \frac{4}{5} \frac{5}{6}$, \&c., more simply than they are already expressed, but for comparing inconcinnous intervals, such as His Lordship's biequal third for instance, with any other intervals : if we examine the " important musical truths" in Stereotype with this view, what do we find, more thin that the biequal third has an approximate ratio of $\frac{2,371,708,245+}{3,000,000,000}$ (page 23)? If we wish to compare this with the triequal quint for instance, whose ratio is stated in the same page, viz. $\frac{3,008,298,850+}{3,000,000,000}$, and are desirous to learn their difference or the interval remaining after the former is taken from the latter; in vain do we search the records of " musical truths" for the mode of accomplishing this. A novice, misled by the term "difference" in the last column of this page, might think his work easy, and attempt to give us the difference of these fractions, already reduced to a common denominator, for the purpose; but on discovering that the least interval had the largest numerator, here our tyro's exertions would probably end. One a little more experienced would discover, that it is a ratio which is to be deducted, and recollecting his school rule for the division of fractions, would proceed to multiply the denominators and numerators together reciprocally, when after proper reduction, $\frac{2,008,298,8.50+}{2,371,708,245 t}$ would appear as the ultimate sc truth" to be come at.

Now those who have done me the honour, of attending to 
the new notation vol. syviii. p. 142, would at once discover, that $354 \mathrm{~s}+7 \mathrm{f}+30 \mathrm{~m}$, and $207 \frac{1}{2} \mathrm{~s}+4 \mathrm{f}+18 \mathrm{~m}$, represent the triequal quint and biequal third respectively, and that the difference of these, or $146 \frac{5}{6} \Sigma+3 f+12 \frac{2}{3} \mathrm{~m}$, admits of an immediate comparison with all the various intervals in the tabic in plate $V$. of the same volume. One simple subtraction woth further show it to be, a minor third flattened $14 \frac{1}{6} \Sigma+1 \frac{1}{3} \mathrm{~m}$, or $2 \frac{1}{6} \Sigma+\frac{1}{3} \mathrm{~m}$ more than the diaschisma or quint-wolf of our noble author: and hundreds of instances might be shown, wherein this notation gives still greater facility to the comparison of intervals with very complex ratios, than it does in the above case; but can His Lordship show a single instance (except the well-known and useful process of reducing large numbers of pence to pounds, shillings, and pence, for some purposes be considered such,) wherein his ingeninus notation by scores, dozens, and odd would possess any advantage over decimal arithmetic ? analogous to the conversion of simple ratios by the new notation into three elementary ratios (or two in some cases) which I have effected for the general comparisons of intervals ? or, can his sapient approvers make out, similar advantages to result from their "cubit" and "measuring rod of Ezekiel," for expressing the Lapland degree?

I have not dropped my design of entering at some future time on a comparison of His Lordship's monochord and equal-beating systems, with the systems of other writers, particularly those which His Lordship has in so summary a way condemned, as I originally proposed, by the help of a table of the temperaments and leats of every concord which can arise in each system respectively: and as I am kindly assisted in the labour of these calculations, by a gentleman of more leisure than myself, with whom His Lordship is well acquainted, be has in the mean time the opportunity through him, of himself anticipating my intended comparisons, and of giving, any further support to his systems, which such comparative evidence will warrant.

I am, sir, your obedient humble servant, 12, Upper Crown Street, Westminster,

JOHN FARJY . March 14, 1809.

LIII. On 

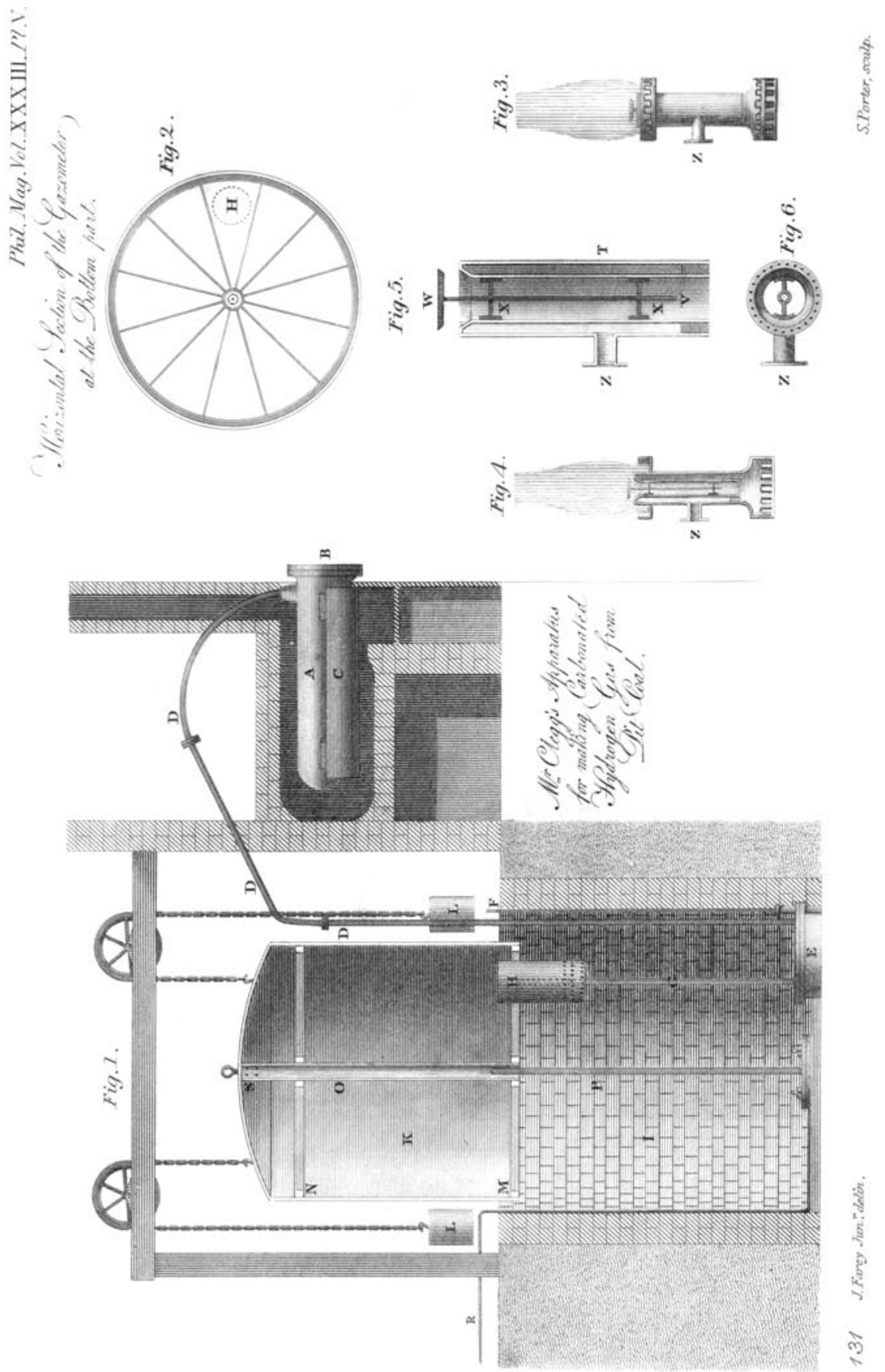